\title{
Effect of capsaicin on substrate oxidation and weight maintenance after modest body-weight loss in human subjects
}

\author{
Manuela P. G. M. Lejeune*, Eva M. R. Kovacs and Margriet S. Westerterp-Plantenga \\ Department of Human Biology, Maastricht University, P. O. Box 616, NL-6200 MD Maastricht, The Netherlands
}

(Received 12 August 2002 - Revised 24 March 2003 - Accepted 13 May 2003)

\begin{abstract}
The aim of the present study was to investigate whether capsaicin assists weight maintenance by limiting weight regain after weight loss of 5 to $10 \%$. In this randomized double-blind placebo-controlled study, ninety-one moderately overweight subjects were randomly assigned to an intensive group that underwent all the measurements, and an extensive group that underwent the same measurements except the metabolism measurements. After a 4-week very-low-energy diet (VLED) intervention, a 3-month weight-maintenance period followed. During weight maintenance, subjects were divided into a capsaicin $(135 \mathrm{mg}$ capsaicin/d) and a placebo group. Body mass was measured before and after the VLED and after 1, 2 and 3 months of weight maintenance. The mean body-mass loss during the VLED was 6.6 (SD 2.0) $\mathrm{kg}(7.8$ (SD 1.8)\% initial body mass), and was not different between the subsequent treatment and placebo group. During weight maintenance, mean $\%$ regain during treatment was not significantly different compared with placebo (33.3 (SD 35.7) $v$. 19.2 (SD 41.8) \%, $P=0.09$ ). RQ was significantly less increased during weight maintenance in the treatment group compared with placebo $(0.04$ (SD 0.06) v. 0.07 (SD 0.05), $P<0.05$ ), indicating a relatively more sustained fat oxidation. Fat oxidation $(\mathrm{g} / \mathrm{h})$ after weight maintenance was higher in the capsaicin group compared with placebo (4.2 (SD 1.1) v. 3.5 (SD 0.9), $P<0.05$ ). These results indicate that capsaicin treatment caused sustained fat oxidation during weight maintenance compared with placebo. However, capsaicin treatment has no limiting effect on 3-month weight regain after modest weight loss.
\end{abstract}

Appetite: Energy expenditure: Fat oxidation

The increasing incidence of obesity is a recognized medical problem in developed countries (Seidell, 1995). Obesity is a major factor for a number of diseases, including CHD, hypertension, non-insulin-dependent diabetes mellitus, pulmonary dysfunction, osteoarthritis and certain types of cancer (Noppa, 1980; Hubert et al. 1983; Kromhout, 1983).

Factors suggested as being related to the development of obesity are decreased physical activity and increased energy intake, especially fat intake. Weight loss and loss of body fat can thus be achieved by reducing energy intake and/or increasing energy expenditure (EE).

Treatment of obesity is beneficial. Weight loss reduces the risk of mortality and morbidity in obese subjects (Van Gaal et al. 1997). Even modest weight loss, 5 to $10 \%$ of the initial body weight, leads to beneficial health effects (Goldstein, 1992; Wing et al. 1992; Van Gaal et al. 1997). Risk factors related to obesity, such as lipid abnormalities and hypertension are positively affected by modest weight loss (Van Gaal et al. 1997). Modest weight loss is a realistic goal for most subjects (Goldstein, 1992; Van Gaal et al. 1997). However, long-term maintenance of the body weight lost can be described as unsuccessful.
Most studies on weight maintenance show that weight regain is usual (Wadden et al. 1988; Kramer et al. 1989; Pasman et al. 1997a,b, 1999), indicating that subjects are not able to change their eating and activity behaviour adequately (Westerterp-Plantenga et al. 1998). Interventions to improve long-term weight maintenance are therefore needed in order to treat obesity effectively. The limited long-term effectiveness of conventional weight management (dietary intervention, physical activity and behavioural therapy) requires alternative weight-reduction strategies. A rapidly growing therapeutic area, largely embraced by the general public, is the use of natural herbal supplements. A wide selection of herbal products are currently being marketed as weight-loss agents.

One of these agents is capsaicin, the pungent principle of hot red pepper. Capsaicin has been reported to reduce adiposity in rats: this can be partly explained by the enhancing effects on energy and lipid metabolism via catecholamine secretion from the adrenal medulla through sympathetic activation of the central nervous system (Kawada et al. 1986, 1988). In a series of human studies, Yoshioka et al. (1995, 1998, 1999, 2001) showed an increase in diet-induced thermogenesis and a decrease in 
RQ immediately after a meal to which capsaicin was added, implying a shift in substrate oxidation from carbohydrate to fat oxidation. This increase in the facultative phase of diet-induced thermogenesis was probably due to $\beta$-adrenergic stimulation (Yoshioka et al. 1995). They also showed a decreased appetite, decreased cumulative food intake (Yoshioka et al. 1999) and increased EE (Yoshioka et al. 1998, 2001) after consumption of capsaicin. Therefore, it is of interest to examine the observations in these short-term experiments on the long term. We hypothesize that capsaicin consumption on the long term may have a limiting effect on body-weight regain after weight loss, through reduced appetite and food intake and through a thermogenic effect.

The aim of the present study was to investigate whether capsaicin may improve weight maintenance by preventing or limiting weight regain after weight loss of 5 to $10 \%$ in moderately overweight subjects.

\section{Subjects and methods}

\section{Subjects}

Male and female subjects ( $n$ 140), aged between 18 and 60 years, were recruited for this study. They underwent a medical screening. Selection resulted in 120 eligible subjects who were in good health, non-smokers, not using medication and at most moderate alcohol users. These were moderately overweight subjects, with a BMI between 25 and $35 \mathrm{~kg} / \mathrm{m}^{2}$. They all gave their written informed consent. The Medical Ethics Committee of the Academic Hospital in Maastricht approved of the study. Subjects were randomized to an extensive group $(n 40)$ that underwent the same protocol as the intensive group ( $n 80)$, but not the metabolism measurements. During the first four weeks, twentythree subjects dropped out due to various reasons: moving house, changing jobs, not being able to cope with the first diet or not being able to fulfil the schedule of visits to the University. Ninety-seven subjects completed the study, i.e. sixty-eight in the intensive group and twenty-nine in the extensive group. Six outliers were removed from the analyses. These were subjects who continued losing weight during weight maintenance or regained more than $100 \%$ weight during weight maintenance. Thus, analyses were based on ninety-one subjects, i.e. sixty-four in the intensive group and twenty-seven in the extensive group.

\section{Body weight and BMI}

Body weight was measured on a digital balance (Seca, model 707, Hamburg, Germany; weighing accuracy of $0.1 \mathrm{~kg}$ ) with subjects in underwear, in a fasted state and after voiding their bladder. Height was measured using a wall-mounted stadiometer (Seca, model 220). BMI was calculated as body weight $(\mathrm{kg}) /$ height $(\mathrm{m})^{2}$.

\section{Waist:hip ratio}

The distribution of fat was investigated by measuring the waist and hip circumferences and calculation of the waist: hip ratio. The waist circumference was measured at the site of the smallest circumference between the rib cage and the iliac crest with the subjects in standing position. The hip circumference was measured at the site of the largest circumference between the waist and the thighs. The waist: hip ratio was calculated by dividing the waist circumference by the hip circumference.

\section{Body composition}

Total body water was measured using the ${ }^{2} \mathrm{H}\left({ }^{2} \mathrm{H}_{2} \mathrm{O}\right)$-dilution technique (Schoeller et al. 1980; Van Marken Lichtenbelt et al. 1994). In the evening, the subjects ingested a dose of ${ }^{2} \mathrm{H}$-enriched water $\left({ }^{2} \mathrm{H}_{2} \mathrm{O}\right)$ after collecting a background urine sample. After consumption of ${ }^{2} \mathrm{H}_{2} \mathrm{O}$ no more fluid or food were consumed. The following morning a urine sample from the second voiding was collected between 08.00 and 10.00 hours. ${ }^{2} \mathrm{H}$ concentrations in the urine samples were measured using an isotope ratio MS (Micromass Optima, Manchester, UK). Total body water was obtained by dividing the measured ${ }^{2} \mathrm{H}$ dilution space by 1.04 (Schoeller et al. 1980). Fat-free mass (FFM) was calculated by dividing the total body water by the hydration factor 0.73. By subtracting FFM from body weight, fat mass (FM) was obtained. Body fat (\%) was calculated as FM expressed as $\%$ body weight.

\section{Attitude towards eating}

To determine whether attitude towards food intake changed during the experiment, a Dutch translation of the three-factor eating questionnaire (TFEQ) was used (Stunkard \& Messick, 1985; Westerterp-Plantenga et al. 1999). The first factor of the TFEQ (F1) measures cognitive restrained eating: control of food intake by thought and will power. The second factor (F2) represents disinhibition: an incidental inability to resist eating cues or inhibition of dietary restraint, and emotional eating. The third factor (F3) examines the subjective feeling of general hunger. In addition, the Herman-Polivy questionnaire (Herman \& Polivy, 1980) was used to determine the frequency of dieting.

\section{Post-absorptive appetite profile}

To determine the post-absorptive appetite profile, hunger and satiety were rated on anchored $100 \mathrm{~mm}$ visual analogue scales in the morning before breakfast after an overnight fast.

\section{Blood variables}

In the morning before breakfast and after an overnight fast, a blood sample of $10 \mathrm{ml}$ was taken and mixed with EDTA to prevent clotting. Plasma was obtained by centrifugation, frozen in liquid $\mathrm{N}_{2}$ and stored at $-80^{\circ} \mathrm{C}$ until further analysis. Plasma glucose concentrations were determined using the hexokinase method (Glucose HK 125 kit; ABX diagnostics, Montpellier, France). The Wako NEFA C-kit (Wako Chemicals, Neuss, Germany) was used to determine non-esterified fatty acid (NEFA) concentrations. Insulin concentrations were measured using a radioimmunoassay kit (Insulin RIA-100; Pharmacia, Uppsala, Sweden). The glycerol kinase method was used to determine glycerol concentrations (Boehringer Mannheim 
GmbH, Mannheim, Germany). Triacylglycerol was measured using the GPO-trinder kit (Sigma Diagnostics Inc., St Louis, MO, USA). The $\beta$-hydroxybutyrate dehydrogenase method (Sigma Diagnostics Inc.) was used to determine $\beta$-hydroxybutyrate concentrations. Leptin concentrations were measured using the human leptin radioimmunoassay kit (Linco Research Inc., St Charles, MO, USA).

\section{Adverse events}

Adverse events during treatment were recorded and the severity and outcome specified.

\section{Resting energy expenditure and substrate oxidation}

Resting EE and substrate oxidation were measured by means of an open-circuit ventilated hood system. Subjects came to the laboratory in the morning by car or by bus to minimize the amount of physical activity before the test. Resting EE was measured with subjects in a fasted state while lying supine for $30 \mathrm{~min}$. Gas analyses were performed by a paramagnetic $\mathrm{O}_{2}$ analyser (Servomex type 500A; Servomex Controls Ltd, Crowborough, Sussex, UK) and an i.r. $\mathrm{CO}_{2}$ analyser (Servomex type 500A), similar to the analysis system described by Schoffelen et al. (1997). Calculation of resting EE was based upon the Weir's formulas (Weir, 1949). RQ was calculated as $\mathrm{CO}_{2}$ produced $/ \mathrm{O}_{2}$ consumed. Fat oxidation was calculated using the following equation (Péronnet \& Massicotte, 1991):

$$
\text { Fat oxidation } \begin{aligned}
(\mathrm{g} / \mathrm{h})= & \left(1.695 \times V_{\mathrm{O}_{2}}(1 / \mathrm{min})-1.701\right. \\
& \left.\times V_{\mathrm{CO}_{2}}(1 / \mathrm{min})\right) \times 60 .
\end{aligned}
$$

\section{Physical activity}

Physical activity level was determined using an uni-axial accelerometer (CSA; Computer Science and Applications Inc., Shalimar, FL, USA) (Ekelund et al. 2000) or a triaxial accelerometer for movement registration (Tracmor; Philips, Eindhoven, The Netherlands) (Goris et al. 2001) for 1 week. Subjects wore the CSA or Tracmor during waking hours on a belt at the back of the waist.

Physical activity level was calculated using the following equation for the CSA (Ekelund et al. 2000):

$$
\begin{aligned}
\text { physical activity level }= & (0 \cdot 000001379 \\
& \times(\text { counts }(n) \text { per } \mathrm{d} \times 5)) \\
& +1 \cdot 113,
\end{aligned}
$$

and the following equation for the Tracmor (Goris et al. 2001):

$$
\begin{aligned}
\text { total } \mathrm{EE}= & -1.259+(1.552 \times \text { resting } \mathrm{EE}) \\
& +(0.076 \times \text { counts }(n) \text { per } \min ),
\end{aligned}
$$

and then:

$$
\begin{aligned}
\text { physical activity level }= & \text { total } \mathrm{EE}(\mathrm{MJ} / \mathrm{d}) / \text { resting } \\
& \operatorname{EE}(\mathrm{MJ} / \mathrm{d}) .
\end{aligned}
$$

The accelerometers were randomized over the two groups. Half of the subjects in the capsaicin group and the placebo group used the CSA, the other half used the Tracmor. Subjects received the same accelerometers every time.

\section{Energy intake}

Energy intake was calculated as total EE plus energy for storage. Energy for storage was calculated from the composition of the energy stored. For the usual energy for storage of FM and FFM, $30 \mathrm{MJ} / \mathrm{kg}$ body-weight gained was used (equation 1). If body-weight gain consisted of only FFM while FM decreased, $52 \mathrm{MJ} / \mathrm{kg}$ FFM gained (Pullar \& Webster, 1977) and $30 \mathrm{MJ} / \mathrm{kg}$ FM lost were used (equation 2):

$$
\begin{aligned}
& \text { energy for storage }(\mathrm{MJ} / \mathrm{d})=\left(\begin{array}{l}
\Delta \text { body weight }(\mathrm{kg}) \\
\times 30) / \mathrm{d}(n),
\end{array}\right. \\
& \text { energy for storage }(\mathrm{MJ} / \mathrm{d}) \\
& \quad=((\Delta \mathrm{FFM}(\mathrm{kg}) \times 52)-(\Delta \mathrm{FM}(\mathrm{kg}) \times 30)) / \mathrm{d}(n) .
\end{aligned}
$$

\section{Very-low-energy-diet period}

After the subject's baseline measurements a very-lowenergy-diet intervention followed for 4 weeks, in order to let the subjects lose weight. The very-low-energy diet (Modifast ${ }^{\circledR}$; Novartis Nutrition, Breda, The Netherlands) was supplied in three sachets per d, dissolved in water to obtain a milk shake, pudding, soup or muesli. Vegetables and fruits were allowed in addition to the very-lowenergy diet. The aim was a body-weight loss of at least $4 \mathrm{~kg}$ per 4 weeks. After this weight-loss period, the measurements described under baseline measurements were repeated (Table 1 )

\section{Weight-maintenance period}

The weight-maintenance period then started. During the weight-maintenance phase, the subjects, divided into two matched groups, received capsaicin or placebo. The capsaicin capsules contained $22.5 \mathrm{mg}$ capsaicin (Naturex, Avignan, Cedex, France) and $202.5 \mathrm{mg}$ vegetable oil. The placebo capsules contained $225 \mathrm{mg}$ vegetable oil. Subjects in both groups had to take two capsules during breakfast, two during lunch and two during dinner. Thus, the total dosage of capsaicin was $135 \mathrm{mg} / \mathrm{d}$ for the capsaicin group and $0 \mathrm{mg}$ capsaicin/d for the placebo group. This dosage of capsaicin was based upon the maximal dosage given in the literature (Yoshioka et al. 1995, 1998, 1999, 2001). Other dosages and types used were from $3 \mathrm{mg}$ per experiment to $126 \mathrm{mg} / \mathrm{d}$ (Yoshioka et al. 1995, 1998, 1999, 2001).

Subjects were stratified for gender, BMI, age, eating behaviour (TFEQ, factor 1) and resting EE, and divided into two groups. A double-blind administration of the supplementation was carried out. Thus, finally forty-two (thirty female, twelve male) subjects participated during the whole experiment in the capsaicin group and fortynine (thirty-eight female, eleven male) subjects in the placebo group. With respect to the group with intensive 


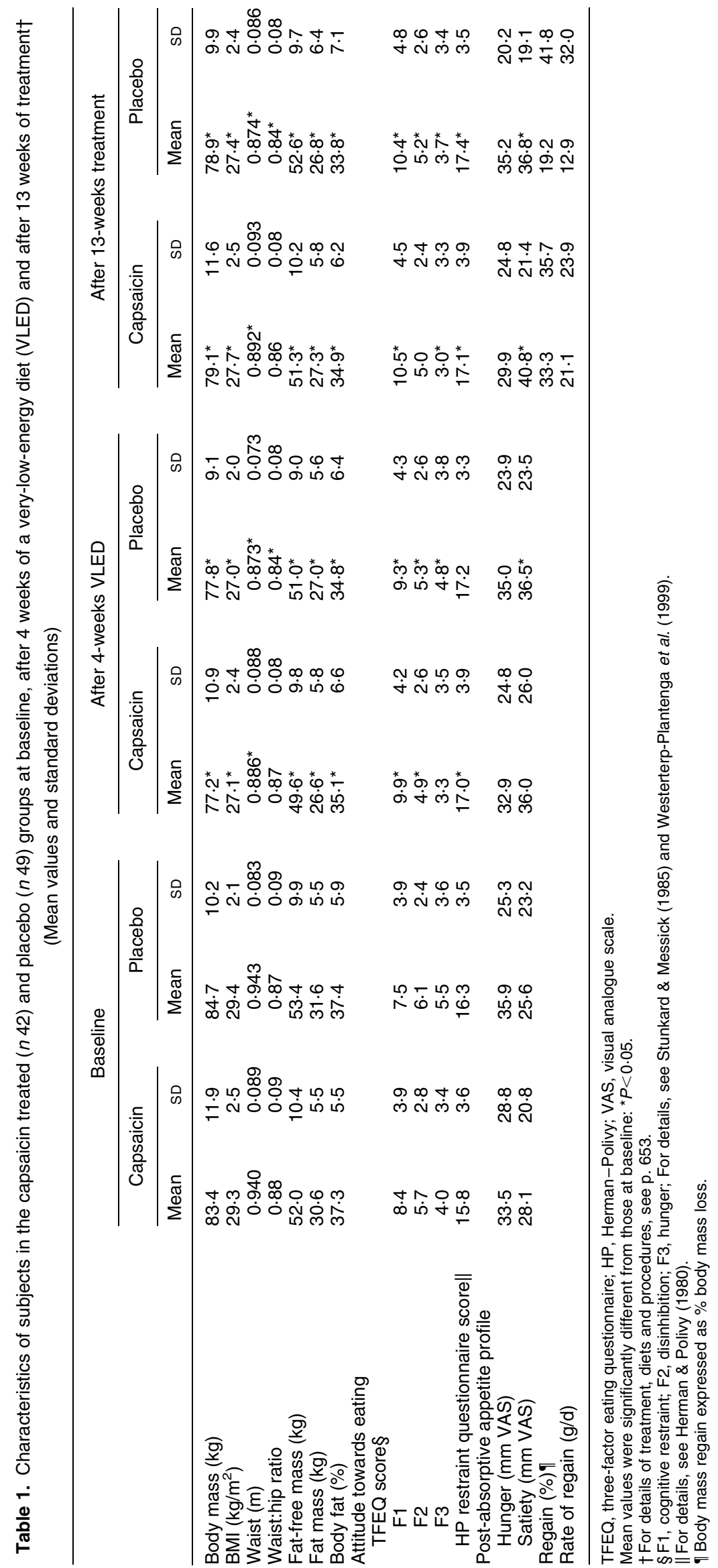


measurements, thirty subjects participated during the whole experiment in the capsaicin group and thirty-six subjects in the placebo group. Ten of the subjects complained about the capsules on the first or second day. They were seen by the responsible medical doctor and advised to use half the dosage. After disclosure of the blinding, it was learnt all these subjects were part of the capsaicin group. Measurements, as described under baseline measurements, were executed again 3 months (i.e. 13 weeks) later. In addition, body weight was determined 1 and 2 months after the start of the weight-maintenance period.

\section{Data analysis}

Results are presented as mean values and standard deviations. A two-factor repeated-measures ANOVA was carried out to determine possible differences between the capsaicin and placebo group in all measured variables over time. When appropriate, a factorial ANOVA was used for analysing differences between the treatment groups. Post hoc analyses were done with the Scheffe $F$ test. A $P$ value $<0.05$ was regarded as statistically significant. Statistical procedures were performed by using Statview SE+Graphics (1988; Abacus Concepts, Berkeley, CA, USA).

\section{Results}

No different effects for men or women were observed. Therefore these results have been taken together.

\section{Very-low-energy-diet period}

During the very-low-energy-diet period the following changes, which did not differ between the subsequent treatment and placebo group, occurred (Table 1). With respect to body-weight loss, the subjects lost a significant amount of body weight, i.e. 6.6 (SD 2.0$) \mathrm{kg}(7.8$ (SD 1.8) \% of their original body weight) $(P<0.001)$. This consisted of 4.1 (SD 1.6) $\mathrm{kg}$ FM and 2.5 (SD 1.7) $\mathrm{kg}$ FFM. The bodyweight results for both groups are presented in Fig. 1. Waist circumference was also significantly reduced over time. Attitude towards eating showed some significant changes over time (Table 1). Cognitive restraint (factor 1, TFEQ) increased significantly, disinhibition (factor 2, TFEQ) and general hunger scores (factor 3, TFEQ) decreased during weight loss (Table 1). Resting EE and RQ decreased during weight loss (Table 2). Total EE decreased in both groups, but only reached significance in the placebo group. The fasting blood variables glucose, insulin, triacylglycerol and leptin showed a decrease with weight loss, and $\beta$-hydroxybutyrate, glycerol (NS) and NEFA showed an increase with weight loss (Table 3).

\section{Weight-maintenance period}

During weight maintenance, body-weight regain, expressed as \% body mass loss, as well as rate of regain, were not significantly different between treatments (Table 1). Cognitive restraint scores stayed significantly higher during the weight-maintenance period compared with baseline

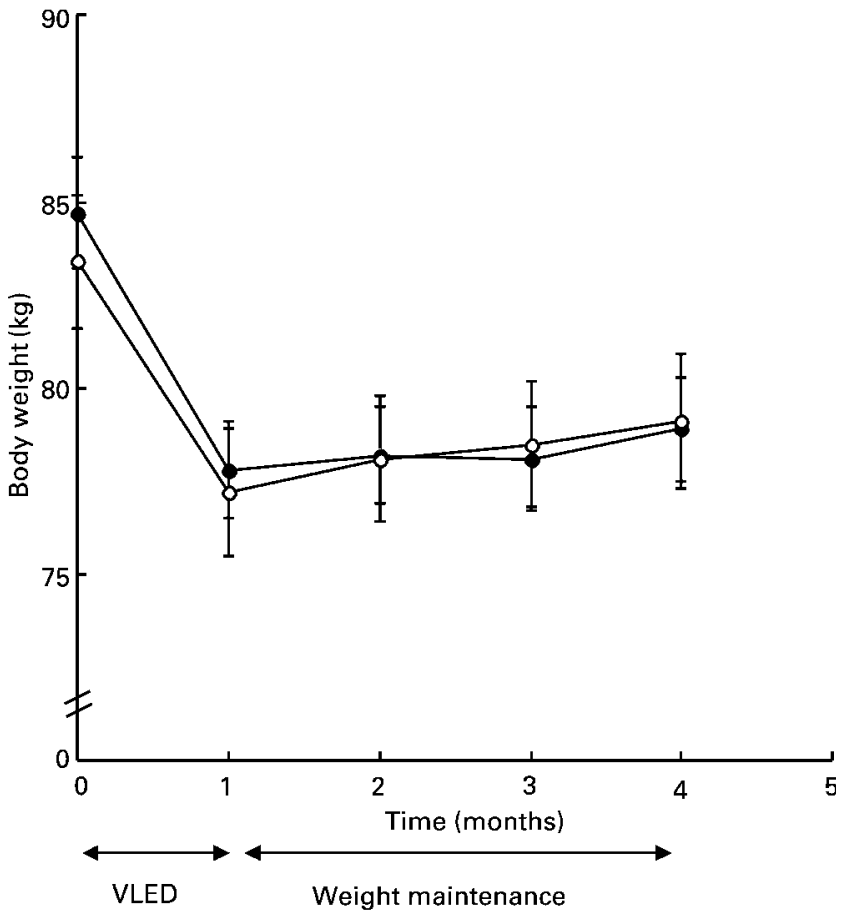

Fig. 1. Change in body weight over time in the capsaicin-treated $(O, n$ 42) and placebo ( $\bullet, n$ 49) groups. VLED, very-low-energy diet. For details of subjects, supplements and procedures, see Table 1 and p. 653. Values are means with their standard errors shown by vertical bars. No significant differences were seen between both groups at any time.

values in both groups. Disinhibition stayed lowered in the placebo group, and general hunger decreased in both groups. Satiety in the fasted state before breakfast increased during weight maintenance in the placebo and in the capsaicin group (Table 1). The hunger scores in the fasted state before breakfast did not change over time in both groups.

The increase in RQ during weight maintenance was significantly smaller in the capsaicin compared with the placebo group (0.04 (SD 0.06$) \quad v$. $0.07 \quad$ (SD 0.05$)$, $P<0.05)$, indicating a smaller decrease in fat oxidation in the capsaicin group than in the placebo group. The increase in RQ was not related to weight regain $(P>0.05)$. Fat oxidation $(\mathrm{g} / \mathrm{h})$ after weight maintenance was higher in the capsaicin group compared with placebo (4.2 (SD 1.1) v. 3.5 (SD 0.9), $P<0.05$ ) (Fig. 2). The increase in resting EE during weight maintenance was significantly higher in the capsaicin compared with placebo group $(0.7$ (SD 0.5) MJ/d v. 0.2 (SD 0.5) $\mathrm{MJ} / \mathrm{d}, P<0.005$ ), although increases in FFM showed no differences between both groups. Resting EE in the placebo group after weight maintenance was still significantly lower compared with baseline values, but FFM was also lower. In the capsaicin group, the resting EE returned to baseline, while FFM was still reduced. To assess possible differences in resting EE adjusted for FFM between groups, we analysed the residuals of the regression of resting EE on FFM (Fig. 3). The residual analysis was done by factorial ANOVA after 3 months of treatment, and showed a trend for a significant difference between the capsaicin and placebo group after 
Table 2. Energy expenditure and substrate oxidation in the capsaicin-treated and placebo groups at baseline, after 4 weeks of a very-lowenergy diet (VLED) and after 13 weeks of treatmentł

(Mean values and standard deviations)

\begin{tabular}{|c|c|c|c|c|c|c|c|c|c|c|c|c|}
\hline & \multicolumn{4}{|c|}{ Baseline } & \multicolumn{4}{|c|}{ After 4-weeks VLED } & \multicolumn{4}{|c|}{ After 13-weeks treatment } \\
\hline & \multicolumn{2}{|c|}{ Capsaicin } & \multicolumn{2}{|c|}{ Placebo } & \multicolumn{2}{|c|}{ Capsaicin } & \multicolumn{2}{|c|}{ Placebo } & \multicolumn{2}{|c|}{ Capsaicin } & \multicolumn{2}{|c|}{ Placebo } \\
\hline Resting EE (MJ/d)§ & $6 \cdot 8$ & $1 \cdot 2$ & $7 \cdot 0$ & 0.9 & $6 \cdot 2^{\star}$ & $1 \cdot 0$ & $6 \cdot 3^{*}$ & 0.7 & $6 \cdot 9$ & $1 \cdot 1$ & $6 \cdot 5^{\star}$ & 0.8 \\
\hline $\mathrm{RQ \S}$ & 0.84 & 0.05 & 0.83 & 0.04 & $0.79^{\star}$ & 0.04 & $0.78^{*}$ & 0.04 & 0.83 & 0.05 & $0.85^{\star}$ & 0.05 \\
\hline Fat oxidation $(g / h) \|$ & $4 \cdot 1$ & $1 \cdot 0$ & $4 \cdot 3$ & 0.9 & $4 \cdot 6$ & $1 \cdot 3$ & $4 \cdot 9^{\star}$ & $1 \cdot 0$ & $4.2 \dagger$ & $1 \cdot 1$ & $3 \cdot 5^{\star}$ & 0.9 \\
\hline Total EE (MJ/d)ף & $10 \cdot 8$ & $1 \cdot 8$ & $10 \cdot 8$ & 1.5 & $9 \cdot 8$ & $1 \cdot 0$ & $9 \cdot 9^{*}$ & $1 \cdot 2$ & $10 \cdot 1$ & $1 \cdot 2$ & $10 \cdot 1$ & 1.4 \\
\hline $\mathrm{EI}(\mathrm{MJ} / \mathrm{d}) \boldsymbol{q}$ & & & & & & & & & $11 \cdot 4$ & 1.5 & $10 \cdot 8$ & $2 \cdot 3$ \\
\hline
\end{tabular}

EE, energy expenditure; PAL, physical activity level; El, energy intake.

Mean values were significantly different from those at baseline: ${ }^{\star} P<0.05$.

Mean value was significantly different from that of the placebo group: $+P<0.05$.

$\ddagger$ For details of subjects, treatment, diets and procedures, see Table 1 and pp. 652-653.

$\S$ Capsaicin $n$ 30, placebo $n 36$.

II Capsaicin $n$ 25, placebo $n 32$

q Capsaicin $n$ 11, placebo $n 18$

treatment $(P=0 \cdot 07)$. Total EE remained significantly lower during weight maintenance compared with baseline values in the placebo group, but FFM was lower as well.

Energy intake, calculated from EE and energy storage, was not significantly different between both groups during weight maintenance.

Insulin and leptin levels stayed significantly lower after treatment compared with baseline in both groups (Table 3 ). Glucose levels in the placebo group and triacylglycerol levels in the capsaicin group stayed significantly lower after treatment compared with baseline values. $\beta$-Hydroxybutyrate, glycerol and NEFA levels almost returned to baseline values during weight regain (Table 3 ). No effect of treatment $\times$ time interaction appeared.

No other adverse events, other than the ten subjects who complained about the capsules and were advised to use half the dosage, were reported. Results of subjects receiving the half dosage or the complete dosage of capsaicin did not differ significantly.

\section{Discussion}

The actual experiment on body-weight maintenance after body-weight loss showed that $135 \mathrm{mg}$ capsaicin/d $v$. placebo did not improve body-weight maintenance in originally moderately overweight men and women, after a modest weight loss of $7.8 \%$. However, we showed that with similar weight regain, substrate oxidation was affected by capsaicin. During weight regain, the increase in RQ was smaller in the capsaicin group, so the decrease in fat oxidation was smaller compared with placebo. The net fat oxidation $(\mathrm{g} / \mathrm{h})$ after weight maintenance was also higher in the capsaicin group compared with placebo. This is in accordance with the suggestion by Yoshioka et al. (1998), who showed a shift in lipid balance during a short-term experiment with capsaicin in Japanese women.

Measurements of habitual food intake are difficult, especially in obese subjects, because of under-reporting energy and fat intake (Goris \& Westerterp, 1999, 2000;

Table 3. Fasting blood variables in the capsaicin-treated $(n 40)$ and placebo $(n 47)$ groups at baseline, after 4 weeks of a very-low-energy diet (VLED) and after 13 weeks of treatment†

(Mean values and standard deviations)

\begin{tabular}{|c|c|c|c|c|c|c|c|c|c|c|c|c|}
\hline & \multicolumn{4}{|c|}{ Baseline } & \multicolumn{4}{|c|}{ After 4-weeks VLED } & \multicolumn{4}{|c|}{ After 13 -weeks treatment } \\
\hline & \multicolumn{2}{|c|}{ Capsaicin } & \multicolumn{2}{|c|}{ Placebo } & \multicolumn{2}{|c|}{ Capsaicin } & \multicolumn{2}{|c|}{ Placebo } & \multicolumn{2}{|c|}{ Capsaicin } & \multicolumn{2}{|c|}{ Placebo } \\
\hline & Mean & SD & Mean & SD & Mean & SD & Mean & SD & Mean & SD & Mean & SD \\
\hline Glucose (mmol/l) & $5 \cdot 7$ & 0.8 & 5.4 & 0.4 & $5 \cdot 3^{*}$ & 0.5 & $5 \cdot 1^{*}$ & 0.3 & $5 \cdot 5$ & 0.5 & $5 \cdot 2^{\star}$ & 0.4 \\
\hline Insulin $(\mu \mathrm{U} / \mathrm{ml})$ & $10 \cdot 5$ & $5 \cdot 1$ & $10 \cdot 0$ & 3.6 & $7 \cdot 2^{\star}$ & $3 \cdot 3$ & $6 \cdot 1^{*}$ & $1 \cdot 8$ & $8 \cdot 3^{*}$ & $3 \cdot 1$ & $7 \cdot 4^{\star}$ & $3 \cdot 1$ \\
\hline $\begin{array}{l}\beta \text {-Hydroxybutyrate } \\
(\mu \mathrm{mol} / \mathrm{l})\end{array}$ & 233.6 & $63 \cdot 7$ & $258 \cdot 3$ & 104.9 & $485 \cdot 8^{*}$ & $270 \cdot 8$ & $575 \cdot 4^{*}$ & $335 \cdot 0$ & $253 \cdot 1$ & $81 \cdot 0$ & $246 \cdot 4$ & $88 \cdot 6$ \\
\hline Glycerol ( $\mu \mathrm{mol} / \mathrm{l})$ & $96 \cdot 4$ & $38 \cdot 9$ & $96 \cdot 9$ & $43 \cdot 0$ & $104 \cdot 1$ & $50 \cdot 3$ & 103.9 & 51.9 & $87 \cdot 6$ & $24 \cdot 7$ & $93 \cdot 0$ & $47 \cdot 1$ \\
\hline NEFA $(\mu \mathrm{mol} / \mathrm{l})$ & $313 \cdot 6$ & $148 \cdot 7$ & $317 \cdot 3$ & $117 \cdot 0$ & $419 \cdot 7^{*}$ & $196 \cdot 4$ & $407 \cdot 4^{\star}$ & $167 \cdot 8$ & $302 \cdot 8$ & $109 \cdot 9$ & 299.5 & $183 \cdot 2$ \\
\hline $\begin{array}{l}\text { Triacylglycerol } \\
(\mathrm{mmol} / \mathrm{l})\end{array}$ & 1.56 & 1.00 & 1.40 & 0.65 & $0.99^{*}$ & 0.55 & $0.98^{*}$ & 0.32 & $1 \cdot 25^{\star}$ & 0.71 & $1 \cdot 27$ & 0.63 \\
\hline Leptin $(\mu \mathrm{g} / \mathrm{l})$ & $20 \cdot 8$ & $10 \cdot 7$ & 21.4 & $9 \cdot 3$ & $9 \cdot 7^{*}$ & $6 \cdot 4$ & $8 \cdot 3^{*}$ & 4.5 & $16 \cdot 8^{*}$ & $9 \cdot 3$ & $17 \cdot 5^{\star}$ & $10 \cdot 7$ \\
\hline
\end{tabular}

NEFA, non-esterified fatty acids.

Mean values were significantly different from those at baseline: ${ }^{*} P<0.05$.

†For details of subjects, treatment, diets and procedures, see Table 1 and pp. 652-653. 


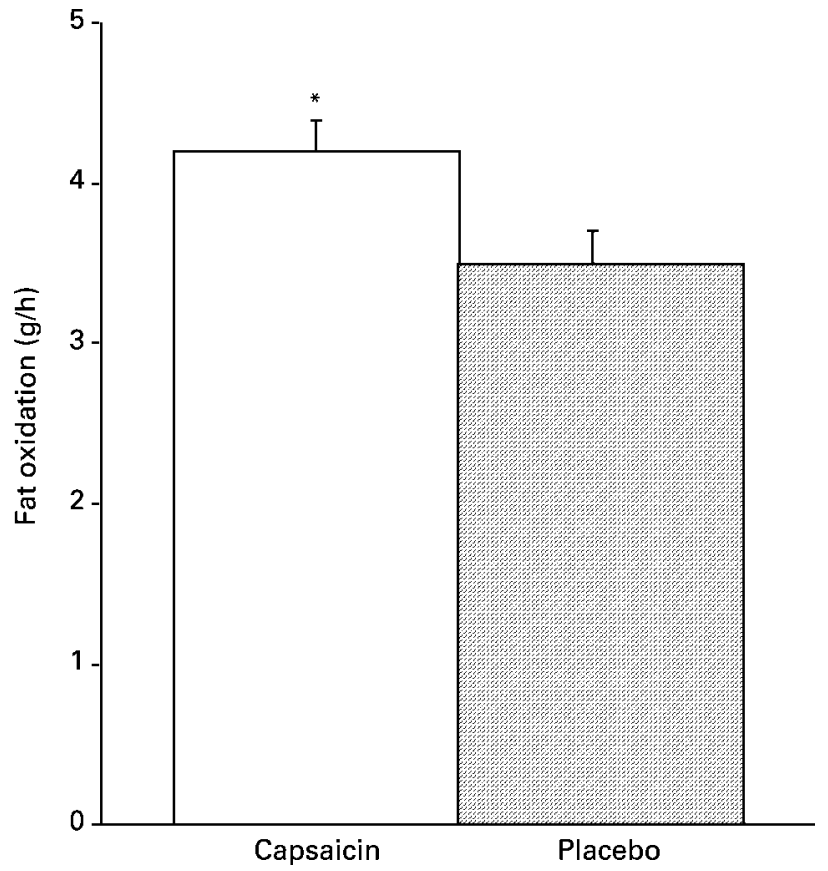

Fig. 2. Fat oxidation $(\mathrm{g} / \mathrm{h})$ after 3 -months weight maintenance in the capsaicin-treated $(n 25)$ and placebo $(n 32)$ groups. For details of subjects, supplements and procedures, see Table 1 and pp. 652653. Values are means with their standard errors shown by vertical bars. Mean value for the capsaicin group was significantly different from that of the placebo group: ${ }^{\star} P<0.05$.

Goris et al. 2000) and this may lead to incorrect conclusions (Goris et al. 2000). Therefore, in the present study, the energy intake during weight maintenance was not recorded, but calculated from EE and energy storage.

Previously, we also observed a lack of a relationship between increase of RQ and body-weight regain after weight loss (Pasman et al. 1998). It seems that the vulnerability for weight gain predicted by a relatively high RQ, as was indicated by Zurlo et al. (1990), Seidell et al. (1992), Ravussin et al. (1993) and Schutz (1995), does not necessarily hold for the situation of weight regain.

Resting EE after weight maintenance returned to baseline in the capsaicin group (although FFM was still lowered), and in the placebo group resting EE was still significantly lower compared with baseline (while FFM was lower too). Since the main determinant of resting EE is FFM (Ravussin \& Bogardus, 1989), the resting EE has to be adjusted for FFM. Therefore, the residuals of the regression of resting EE on FFM were analysed. This showed a trend for an increased resting EE as a function of FFM in the capsaicin group, compared with placebo. Yoshioka et al. (1995) reported an increase in EE after a meal containing red pepper, which was probably explained by $\beta$-adrenergic stimulation. A low metabolic rate after weight reduction is a risk factor for subsequent weight regain (Ravussin \& Bogardus, 1989). However, here the normalized resting metabolic rate in the capsaicin group could not prevent weight regain.

The lack of a relationship between body-weight regain and RQ might explain the lack of a difference in regain between the groups. This emphasizes again that a relatively

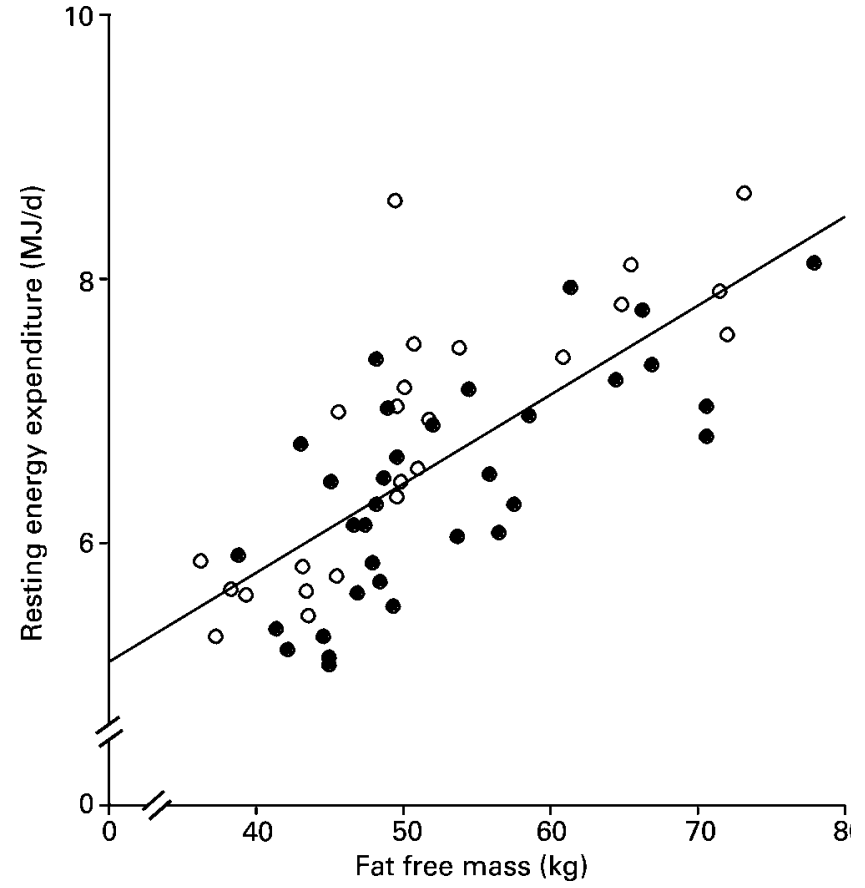

Fig. 3. Resting energy expenditure after weight maintenance as a function of fat-free mass after weight maintenance in the capsaicintreated $(0 ; n 21)$ and placebo $(0, n 28)$ groups. The regression equation is: resting energy expenditure $(\mathrm{MJ} / \mathrm{d})=0.07 \times$ fat-free mass $(\mathrm{kg})+3.1(P<0.0001, r 0.74)$.

low RQ may prevent weight gain (Zurlo et al. 1990; Seidell et al. 1992; Ravussin et al. 1993; Schutz, 1995), which does not mean that an artificially lowered RQ during regain prevents or limits weight regain. Moreover, the relative increase of resting EE as a function of FFM also could not limit weight regain. The relatively lower RQ and higher resting EE did not result in a relatively higher FFM and lower FM in the capsaicin group. It may be that the capsaicin effects, although clearly present, were too small to limit regain of body weight. Furthermore, the regain results showed large individual differences. Even after removing the outliers, the variance of the regain results remains relatively high.

The question of whether subjects get accustomed to capsaicin in the long term is of interest. The Japanese women studied by Yoshioka et al. (1998) were used to spicy foods, but still showed an increase in fat oxidation following red pepper ingestion. The present observations are also in accordance with this, i.e. continuing capsaicin supplementation for 3 months, in subjects who were not used to capsaicin in their habitual diet, still appeared to stimulate fat oxidation. In addition, similarly to the observations of Yoshioka et al. $(1995,1998,1999,2001)$ we did not find different results between different dosages of capsaicin. Compliance to capsaicin consumption in our present study was shown in that all subjects who appeared to have consumed the capsaicin capsules had mentioned a somewhat burning feeling in their stomach every time they came to the University. Here, a subject-specific sensitivity may play a role (Yoshioka et al. 1998). Because the use of capsaicin may cause habituation in the long term, we used a higher dosage compared with the short-term 
experiments of Yoshioka et al. (1995, 1998, 1999, 2001). Since all our subjects reported not using red pepper frequently in their diet, our present dosage may have been relatively high.

The hunger scores in the fasted state before breakfast did not change over time in both groups. Yoshioka et al. (1999) found a decrease in hunger after breakfast with red pepper and before lunch. Therefore a decrease in hunger due to capsaicin consumption might be a shortterm rather than a long-term effect. Here, habituation may have played a role.

Eating behaviour, as measured by the TFEQ, showed an improved profile, i.e. more cognitive restraint, less disinhibition and hunger after the weight-loss period. This is similar to previous observations (Clark et al. 1994; Pekkarinen et al. 1996; Westerterp-Plantenga et al. 1998; Pasman et al. 1999). Previously, we showed an inverse relationship between increase in cognitive restraint during weight loss and weight regain thereafter (Westerterp-Plantenga et al. 1998). However, this relationship failed to reach significance (capsaicin group $P=0 \cdot 1$, placebo group $P=0.06$ ) in the present study.

Regarding the beneficial effects of weight loss, after the treatment period body mass, $\%$ body fat and waist circumference were still significantly reduced compared with baseline. As often seen during weight loss, the fasting blood variables glucose, insulin, triacylglycerol and leptin showed a decrease with weight loss, and $\beta$-hydroxybutyrate, glycerol and NEFA showed an increase with weight loss. The beneficial effects of weight loss were still present after treatment for glucose, insulin, triacylglycerol and leptin, whereas the levels of $\beta$-hydroxybutyrate, glycerol and NEFA returned to baseline.

In conclusion, the short-term observation by Yoshioka et al. (1998), i.e. a larger fat oxidation due to consumption of capsaicin, also holds on the long term, i.e. during weight regain. The short-term effect on appetite reported by Yoshioka et al. (1999) did not appear on the long term. However, the effects of capsaicin in the longer term did not sustain weight maintenance in comparison with placebo, probably because an effect on body composition was not achieved.

\section{Acknowledgements}

We thank Ilse Nijs, Joan Senden, Wendy Sluijsmans and Loek Wouters for their contribution to the study. This study was supported by Novartis CH (Nyon, Switzerland).

\section{References}

Clark MM, Marcus BH, Pera V \& Niaura R (1994) Changes in eating inventory scores following obesity treatment. Int $J$ Eat Disord 15, 401-405.

Ekelund U, Yngve A, Sjöström M \& Westerterp KR (2000) Field evaluation of the computer science and application's inc. activity monitor during running and skating training in adolescent athletes. Int J Sports Med 21, 586-592.

Goldstein DJ (1992) Beneficial effects of modest weight loss. Int J Obes 16, 397-415.
Goris AH \& Westerterp KR (1999) Underreporting of habitual food intake is explained by undereating in highly motivated lean women. $J$ Nutr 129, 878-882.

Goris AH \& Westerterp KR (2000) Improved reporting of habitual food intake after confrontation with earlier results on food reporting. Br J Nutr 83, 363-369.

Goris AH, Westerterp-Plantenga MS \& Westerterp KR (2000) Undereating and underrecording of habitual food intake in obese men: selective underreporting of fat intake. Am J Clin Nutr 71, 130-134.

Goris AHC, Meijer EP, Kester A \& Westerterp KR (2001) Use of a triaxial accelerometer to validate reported food intakes. Am J Clin Nutr 73, 549-553.

Herman CP \& Polivy J (1980) Restrained eating. In Obesity, pp. 208-224 [AJ Stunkard, editor]. Philadelphia, PA: W. B. Saunders.

Hubert HB, Feinleib M, McNamara PM \& Castelli WP (1983) Obesity as an independent risk factor for cardiovascular disease: a 26-year follow-up of participants in the Framingham Heart Study. Circulation 67, 968-977.

Kawada T, Hagihara K \& Iwai K (1986) Effects of capsaicin on lipid metabolism in rats fed high fat diet. J Nutr 116, $1272-1278$.

Kawada T, Sakabe S, Watanabe T, Yamamoto M \& Iwai K (1988) Some pungent principles of spices cause the adrenal medulla to secrete catecholamine in anesthesized rats. Proc Soc Exp Biol Med 188, 229-233.

Kramer FM, Jeffery RW, Forster JL \& Snell MK (1989) Longterm follow-up of behavioral treatment for obesity: patterns of weight regain among men and women. Int J Obes 13, 123-136.

Kromhout D (1983) Body weight, diet, and serum cholesterol in 871 middle-aged men during 10 years of follow-up (the Zutphen Study). Am J Clin Nutr 38, 591-598.

Noppa H (1980) Body weight change in relation to incidence of ischemic heart disease and change in risk factors for ischemic heart disease. Am J Epidemiol 111, 693-704.

Pasman WJ, Saris WH \& Westerterp-Plantenga MS (1998) Predictors of weight maintenance. Obes Res 7, 43-50.

Pasman WJ, Saris WHM, Muls E, Vansant G \& WesterterpPlantenga MS (1999) The effect of exercise training on longterm weight maintenance in weight-reduced men. Metabolism 48, 15-21.

Pasman WJ, Westerterp-Plantenga MS, Muls E, Vansant G, Van Ree J \& Saris WHM (1997a) The effectiveness of longterm fiber supplementation on weight maintenance in weight reduced women. Int J Obes 21, 548-555.

Pasman WJ, Westerterp-Plantenga MS \& Saris WHM (1997b) The effectiveness of long-term supplementation of carbohydrate, chromium, fiber and caffeine on weight maintenance. Int J Obes 21, 1143-1151.

Pekkarinen T, Takala I \& Mustajoki P (1996) Two year maintenance of weight loss after a VLCD and behavioural therapy for obesity: correlation to the scores of questionnaires measuring eating behaviour. Int J Obes 20, 332-337.

Péronnet F \& Massicotte D (1991) Table of nonprotein respiratory quotient: an update. Can J Sport Sci 16, 23-29.

Pullar JD \& Webster AJF (1977) The energy cost of fat and protein deposition in the rat. Br J Nutr 37, 355-363.

Ravussin E \& Bogardus C (1989) Relationship of genetics, age, and physical fitness to daily energy expenditure and fuel utilization. Am J Clin Nutr 49, 968-975.

Ravussin E, Fontvieille AM, Swinburn BA \& Bogardus C (1993) Risk factors for the development of obesity. Ann N Y Acad Sci 683, $141-150$.

Schoeller DA, Van Santen E, Peterson DW, Diez W, Jaspan J \& Klein PD (1980) Total body water measurement in humans with ${ }^{18} \mathrm{O}$ and ${ }^{2} \mathrm{H}$ labeled water. Am J Clin Nutr 33, 2686-2693. 
Schoffelen PFM, Westerterp KR, Saris WHM \& Ten Hoor F (1997) A dual respiration chamber with automated calibration. J Appl Physiol 83, 2064-2072.

Schutz Y (1995) Abnormalities of fuel utilization as predisposing to the development of obesity in humans. Obes Res 3, 173S-178S

Seidell JC (1995) Obesity in Europe. Obes Res 3, Suppl. 2, 249s-259s.

Seidell JC, Muller DC, Sorkin JD \& Andres R (1992) Fasting respiratory exchange ratio and resting metabolic rate as predictors of weight gain: the Baltimore Longitudinal Study on Aging. Int J Obes 16, 667-674.

Stunkard AJ \& Messick S (1985) The three factor eating questionnaire to measure dietary restraint, disinhibition and hunger. J Psychol Res 29, 71-83.

Van Gaal LF, Wauters MA \& De Leeuw IH (1997) The beneficial effects of modest weight loss on cardiovascular risk factors. Int J Obes 21, Suppl. 1, S5-S9.

Van Marken Lichtenbelt WD, Westerterp KR \& Wouters L (1994) Deuterium dilution as a method for determining total body water: effect of test protocol and sampling time. $\mathrm{Br} J$ Nutr 72, 491-497.

Wadden TA, Stunkard AJ \& Liebschutz J (1988) Three-year follow-up of the treatment of obesity by very low calorie diet, behavior therapy, and their combination. J Consult Clin Psychol 56, 925-928.

Weir JBDV (1949) New methods for calculating metabolic rate with special references to protein metabolism. $J$ Physiol 109, 1-9.
Westerterp-Plantenga MS, Kempen KPG \& Saris WHM (1998) Determinants of weight maintenance in women after diet-induced weight reduction. Int J Obes 22, 1-6.

Westerterp-Plantenga MS, Rolland V, Wilson SAJ \& Westerterp KR (1999) Satiety related to $24 \mathrm{~h}$ diet-induced thermogenesis during high protein/carbohydrate vs. high fat diets measured in a respiration chamber. Eur J Clin Nutr 53, 495-502.

Wing RR, Jeffery RW, Burton LR, Thorson C, Kuller LH \& Folsom AR (1992) Change in waist-hip ratio with weight loss and its association with change in cardiovascular risk factors. Am J Clin Nutr 55, 1086-1092.

Yoshioka M, Doucet E, Drapeau V, Dionne I \& Tremblay A (2001) Combined effects of red pepper and caffeine consumption on $24 \mathrm{~h}$ energy balance in subjects given free access to foods. Br J Nutr 85, 203-211.

Yoshioka M, Lim K, Kikuzato S, et al. (1995) Effects of red-pepper diet on the energy metabolism in men. J Nutr Sci Vitaminol 41, 647-656.

Yoshioka M, St-Pierre S, Drapeau V, et al. (1999) Effects of red pepper on appetite and energy intake. Br J Nutr 82, $115-123$.

Yoshioka M, St-Pierre S, Suzuki M \& Tremblay A (1998) Effects of red pepper added to high-fat and high-carbohydrate meals on energy metabolism and substrate utilization in Japanese women. Br J Nutr 80, 503-510.

Zurlo F, Lillioja S, Esposito-Del Puente A, et al. (1990) Low ratio of fat to carbohydrate oxidation as predictor of weight gain: study of 24-h RQ. Am J Physiol 259, E650-E657. 